\title{
Estado y Pueblo Mapuche. Una mirada desde el Derecho y las políticas públicas, Francisco Bedecarratz S. (director). Santiago de Chile, RIL Editores y Universidad Autónoma de Chile, 2020
}

\section{State and Mapuche people. A look from the Law and public policies, Francisco Bedecarratz S. (Director). Santiago, RIL Editores and Universidad Autónoma de Chile, 2020}

Andrea Lucas Garín ${ }^{1}$

\section{RESUMEN}

Las interrelaciones entre el Pueblo Mapuche y del Estado de Chile desde una perspectiva jurídica son presentadas en este libro en base a cuatro pilares: Derechos Fundamentales, Formas de Estado, Orden y Seguridad Pública y Fomento Económico, Social y Cultural; todas temáticas que merecen reflexiones frente a un debate constituyente cercano.

Palabras clave: Pueblos indígenas - Estado de Chile - Reforma constitucional - Políticas públicas

\section{ABSTRACT}

The interrelations between the Mapuche People and the State of Chile from a legal perspective are presented in this book based on four pillars: Fundamental Rights, Forms of State, Order and Public Security and Economic, Social and Cultural Promotion; all issues that deserve reflections in the face of the proximity of a constitutional debate.

Keywords: Indigenous peoples - State of Chile - Constitutional reform - Public policies

Doctora en Derecho y Ciencias Sociales por la Universidad Nacional de Córdoba y directora del Instituto de Investigación en Derecho de la Universidad Autónoma de Chile. Correo: andrea.lucas@uautonoma.cl 
El sentido de pertenencia es algo propio del ser humano. Sin embargo, pensamos que esta no es una cualidad exclusiva de las personas, sino que también se encuentra en las instituciones, lo que se manifiesta en esta obra que acaba de ver la luz. La Universidad Autónoma de Chile — junto a RIL Editores- nacida en Temuco para hacer frente a las necesidades de la región de contar con profesionales capacitados, hoy nos presenta este libro que trae aportes para las reflexiones de las interrelaciones del Pueblo Mapuche y del Estado de Chile, las que hoy más que nunca se presentan como necesarias e imprescindibles.

Con dedicación y compromiso, Francisco Bedecarratz Scholz dirige este libro colectivo que presenta diferentes miradas de las relaciones entre pueblos originarios y el Estado chileno de investigadores, profesores y estudiantes de pregrado y doctorado, que con absoluta libertad presentan sus posturas, en muchas ocasiones encontradas respecto a las temáticas abordadas.

Dieciocho autores en quince capítulos desarrollan una paleta de tópicos que asegura una perspectiva jurídica muy completa y que nos permiten, de un modo acabado, comprender las diferentes visiones jurídicas tocadas principalmente por esta obra colectiva.

El libro está fraccionado en cuatro pilares: Derechos Fundamentales, Formas de Estado, Orden y Seguridad Pública y Fomento Económico, Social y Cultural; todas temáticas que merecen reflexiones frente a un proceso constituyente en camino y ante los hechos que desde los conflictos reales requieren soluciones nuevas.

De esos quince capítulos, ocho autores son investigadores del Instituto de Investigación en Derecho de la Universidad Autónoma de Chile, por lo que su participación en esta obra nos da cuenta del trabajo colaborativo entre sedes que se lleva adelante y que nos permite desde la investigación jurídica hablar un mismo idioma.

Debe señalarse que la obra es el resultado de las Terceras Jornadas Nacionales de Facultad de Derecho de la Universidad Autónoma de Chile, un evento anual que reúne a profesores, investigadores, estudiantes e invitados en torno a distintas temáticas que van cambiando año a año.

La exposición de apertura de Sebastián Donoso Rodríguez realmente arma el escenario donde las temáticas se desenvolverán. Incluye información del Censo, donde da cuenta que un 13\% de la población se declara perteneciente a alguna población indígena (p. 24), marcando una diferencia abismal del Censo de 2002 donde solo un 4,6\% de la población lo hacía en tal sentido. También incluye un breve recorrido de las iniciativas legislativas que se ocupan del tema, y nos brinda un dato relevante que La Araucanía es la región del país con mayor índice de pobreza, esto último lo que confirma que la vulnerabilidad no se presenta sola sino acompañada. Habla de brechas racional, emocional, teórica y cultural (p. 27); del consenso para el reconocimiento constitucional de pueblos indígenas (p. 29). Se ocupa de las claves para construir una mirada y de los grandes temas pendientes.

El primer capítulo sobre Derechos Fundamentales permite a Regina Díaz Tolosa preguntarse si se justifica implementar medidas de discriminación positiva a favor de los pueblos originarios (p. 35), a la luz del Derecho Internacional de los Derechos Humanos. La autora opina que de la mano del Convenio No 169 de la Organización Internacional del Trabajo (OIT) con el nivel de adhesión que cuenta, se asegura una protección convencional en desarrollo aún no cristalizada. Da soluciones a favor de que los pueblos originarios son grupo vulnerable y requieren de una protección especial que considere mecanismos de discriminación positiva (p. 56). 
Juan Jorge Faundes Peñafiel aborda de modo panorámico el derecho fundamental a la identidad cultural de los pueblos indígenas en el contexto de nuestro continente y, del ordenamiento jurídico de Chile desde una mirada de políticas públicas, atendiendo especialmente los estándares de la Corte Interamericana de Derechos Humanos. Aquí téngase presente que su capítulo fue escrito con anterioridad del "Caso comunidades indígenas miembros de la asociación Lhaka Honhat (nuestra tierra) vs. Argentina” (2020), hito que confirma todos los puntos desarrollados por Faundes Peńafiel en este capítulo. A mayor abundamiento, la Corte Interamericana DDHH, en la sentencia Lhaka Honhat, consagra el derecho de las personas a disfrutar de su propia cultura porque guarda relación con los modos de vida estrechamente asociados al territorio y al uso de los recursos de los miembros de comunidades indígenas, entre otras potentes afirmaciones ${ }^{2}$.

Luego de un recorrido regional del derecho fundamental a la identidad cultural de los pueblos indígenas, el autor reconoce la labor de la Corte Interamericana DDHH de dotar de contenido a este derecho mediante estándares (p. 204), al mismo tiempo que reconoce la labor que la jurisprudencia judicial en Chile ha hecho de un modo evolutivo en ocuparse del derecho a la identidad cultural desde la aplicación del Convenio No 169 de la Organización Internacional del Trabajo (OIT).

Desde la sede Talca, Jhenny Rivas Alberti asume el derecho a la consulta previa de los pueblos indígenas con una mirada comparada; aborda la pregunta de si el derecho a la consulta previa es un derecho en Chile desde el llamado 'bloque de constitucionalidad'. Además, Rivas Alberti revisa las características de la consulta previa de un modo ordenado y práctico. Concluye afirmando que la participación de las comunidades étnicas es un presupuesto y un mecanismo para resguardar la libre determinación, la autonomía y los derechos reconocidos en el Convenio No 169 de la OIT.

Antonio Muñoz Aunión y Glorimar Alejandra León Silva vuelven sobre el proceso de consulta previa del Convenio No 169 de la OIT, esta vez desde una perspectiva internacional, señalando las dificultades relacionadas con la ingeniería de la consulta. Finalizan marcando una serie de obligaciones que deben garantizar los estados para que proceda la consulta; además evalúan las contribuciones que ha realizado la consulta al Derecho Internacional postcolonial.

El capítulo segundo, titulado "Formas de Estado", es encabezado por Marcela Inés Peredo Rojas, quien se enfoca en la tradición constitucional chilena y el reconocimiento de los pueblos originarios en la Constitución. De partida, la autora explica que la Constitución en Chile se ha abstenido de ocuparse de los pueblos originarios. Sin dudas, la actualidad de este capítulo se reactiva frente a un proceso constitucional en ciernes, donde el reconocimiento de los pueblos originarios será una pregunta de cajón del constituyente.

Peredo Rojas recorre el Constitucionalismo Latinoamericano (p. 166 y ss) de estos últimos años; también revisa los proyectos de reforma constitucional en estado parlamentario (p. 168). De modo expreso, la autora estructura su juicio sobre el tema (p. 172) y se concentra en explicar por qué la tradición chilena constitucional no ha incluido a los pueblos originarios y si ha delegado el asunto a la ley (p. 175).

El artículo de Juan Pablo Díaz Fuenzalida se concentra en el elemento territorio del Estado y cómo este cambia desde las perspectivas clásicas del territorio como elemento del Estado, a la que plantea el territorio

Faundes, Juan Jorge, Carmona, Cristóbal y Silva, Pedro Pablo (2020). "La Corte Interamericana de Derechos Humanos. Hermenéutica del derecho al medio ambiente sano, a la identidad cultural y a la consulta, a la luz de la sentencia "Lhaka Honhat (nuestra tierra) vs. Argentina (2020)"”, Revista Brasileira de Políticas Públicas. Vol. 10, № 2. 
como sujeto (p. 182), incluyendo además la cosmovisión de los pueblos originarios y el medio ambiente que muy novedosamente abordan tanto la Constitución de Bolivia como la de Ecuador. Un análisis del llamado "constitucionalismo andino" que es muy útil frente a un debate constituyente cercano.

Dos estudiantes de la carrera de Derecho, Hanz Hoffhein Escalona y Jaime González Orellana, se ocupan del reconocimiento constitucional de los pueblos indígenas, pero enfocándose en la jurisprudencia de la Corte Interamericana de Derechos Humanos. Destacamos la labor seria de análisis de jurisprudencia que nos brinda este artículo en base al contexto interamericano.

Por su parte, Fátima El Fakih Rodríguez se ocupa de "Estado y pueblos indígenas en Chile: desafíos emergentes para un derecho pluralista", sentando las bases de los desafíos presentes y futuros que tiene Chile para la construcción de un derecho pluralista aún en construcción.

Esta sección es cerrada por Benoît Delooz Brochet, que ofrece una visión de la descentralización asimétrica, que permite revisar cómo Francia ha abordado con soluciones descentralizadas territoriales problemáticas similares, con particular referencia a los entes territoriales de ultramar.

La parte tercera "Orden y seguridad pública" es iniciada por Alexander Espinoza Rausseo, que se ocupa de los estados de excepción y de la intervención de las Fuerzas Armadas (téngase presente que las jornadas fueron mucho antes de octubre de 2019), y del efecto irradiante de los derechos fundamentales que aborda el autor de un modo ameno e integral. Considera el derecho alemán para hacer el parangón con Chile.

En el capítulo "El derecho penal chileno como respuesta inadecuada al conflicto cultural en la Araucanía", Roberto Navarro Dolmestch nos explica el denominado "conflicto Mapuche", el que califica de "conflicto cultural”, enfocándose en el déficit democrático que el sistema punitivo presenta. De manera fundamentada, el autor sostiene que dicho déficit se relaciona con la visión hegemónica de la sociedad que el derecho penal sustenta, lo que lo lleva a desconocer e ignorar los intereses y la visión mapuche sobre el mundo y sus relaciones.

Al final, contamos con un capítulo cuarto dedicado al "Fomento económico, social y cultural", en el cual Juan Carlos Cisternas Friz se ocupa de manera crítica de la Ley Lafkenche N²0.249, del año 2008 sobre Espacio Costero Marino de los Pueblos Originarios (ECMPO). El autor aborda los problemas de regulación que conlleva la ley para los distintos operadores, determinando que influya negativamente en el sistema productivo que pretende proteger.

Conocedora de la región de la que escribe, Hellen Pacheco Cornejo combina dos temáticas que a simple vista pueden parecer alejadas: la cultura indígena y la propiedad intelectual, que han generado fricciones ante el avance del uso comercial que se está realizando de las manifestaciones culturales de los pueblos originarios De un modo claro y contundente, la autora sostiene que es posible generar protecciones a partir de visiones jurídicas y tecnológicas de la cultura indígena.

Por último, Marcia Molina Pezoa presenta el trabajo "La posesión notoria del estado civil en la Ley $\mathrm{N}^{\circ}$ 19.253”, que dispone que la posesión notoria del estado civil se considerará un título suficiente para constituir los mismos derechos y obligaciones a favor de los indígenas, igual que las leyes comunes, que emanen de la filiación legítima y del matrimonio civil. Este trabajo se hace cargo de las diferencias que presenta esta norma, llamada ley indígena, con la posesión notoria del estado civil regulada por el Código Civil y de sus consecuencias en los procedimientos judiciales. Destaca la labor que los tribunales realizan cuando deben fallar estas causas. 
Felicitamos a los autores y al director por sus aportes cristalizados en esta obra colectiva, así como a la Editorial RIL y a la Universidad Autónoma de Chile por este esfuerzo editorial.

Este recorrido que hemos realizado de manera resumida es una invitación para leer esta obra necesaria sobre Chile, los pueblos originarios, el Estado, los derechos relacionados con particular referencia a la consulta previa, entre varias temáticas. Asimismo, plantean la pregunta del reconocimiento constitucional de los pueblos originarios que el futuro próximo, pensamos, permitirá responder.

Los autores nos muestran su opinión sobre el tema. La invitación es a leer esta obra y poder, cada uno, responder esta pregunta, imprescindible para un Chile que está cambiando. 